\title{
Gorontalo
}

\section{Manajement Research}

Vol. 2 No. 2 Oktober 2019

P-ISSN: 2614-5197, E-ISSN: 2614-5189

\section{The Effect Of Personal Selling And Quality Service Towards Saving Decisions At PT Bank Danamon Indonesian Tbk Katamso Medan Branch}

\section{Pengaruh Personal Selling Dan Kualitas Pelayanan Terhadap Keputusan Menabung Pada PT Bank Danamon Indonesia Tbk Cabang Katamso Medan}

\author{
Jamaluddin'),William 2),Vennolia'),Iin Keristi Bangun ${ }^{4)}$ \\ Prodi Manajemen Pemasaran, Fakultas Ekonomi Universitas Prima Indonesia \\ Jl. Sekip, Kec. Medan Petisah Medan \\ email : jamal.putra08@gmail.com \\ william.su97@hotmail.com \\ vennoliachenn@gmail.com \\ cristybangun33@gmail.com
}

\begin{abstract}
This study aims to determine and analyze the influences of personal selling, service quality, and saving decision at PT. Bank Danamon Indonesia Tbk Katamso Branch. Poor personal selling and the service quality of Bank Danamon that still have not able to satisfy customers led to decreasing saving decisions at PT. Bank Danamon Indonesia Tbk Katamso Medan Branch. The research methodology used in this study is quantitative approach and the nature of this study is explanatory descriptive. The analytical method used in this research is multiple linear analysis. The population used is all customers of PT. Bank Danamon Katamso Medan Branch in total of 629 customers chosen at random. Determination of the sample in this study is using Slovin formula. The results shows that personal selling and service quality has a significant effect on saving decisions at PT. Bank Danamon Indonesia Tbk Katamso Medan Branch. From the analysis of the factors that influence saving decisions, it can be seen that between the two variables analyzed, the most dominant factor influences saving decisions is service quality variable. This is proven by the results of the calculation of $t$ count of each variable. The conclusion of this research is that in a series and partially shows that personal selling and service quality significantly influence the decision to save at PT. Bank Danamon Indonesia Tbk Katamso Medan Branch.
\end{abstract}

Keyword : Personal Selling; Quality Of Service; Saving Decision

\begin{abstract}
ABSTRAK
Penelitian ini bertujuan untuk mengetahui dan menganalisis pengaruh personal selling, kualitas layanan dan keputusan menabung pada PT. Bank Danamon Indonesia Tbk Cabang Katamso. Buruknya personal selling yang dimiliki Bank Danamon dan kualitas layanan yang belum mampu unuk memuaskan nasabah menyebabkan penurunan
\end{abstract}


keputusan menabung pada PT. Bank Danamon Indonesia Tbk Cabang Katamso Medan. Metode penelitian yang digunakan dalam penelitian ini adalah pendekatan kuantitatif dan sifat penelitian ini adalah desktiptif explanatory. Metode analisis yang digunakan adalah analisis linier berganda. Populasi yang digunakan adalah seluruh nasabah PT. Bank Danamon Cabang Katamso Medan yang berjumlah 629 nasabah yang dipilih secara acak. Penentuan sampel dalam penelitian ini menggunakan rumus slovin. Hasil penelitian menunjukkan bahwa personal selling dan kualitas pelayanan berpengaruh signifikan terhadap keputusan menabung pada PT. Bank Danamon Indonesia Tbk Cabang Katamso Medan. Dari hasil analisis mengenai faktor-faktor yang mempengaruhi keputusan menabung, dapat dilihat bahwa antara kedua variabel yang dianalisis, maka yang paling dominan memengaruhi keputusan menabung adalah variabel kualitas pelayanan. Hal tersebut dibuktikan dengan hasil perhitungan $t_{\text {hitung }}$ masing-masing variabel. Kesimpulan pada penelitan ini adalah secara serepak dan parsial menunjukkan bahwa personal selling dan kualitas pelayanan berpengaruh signifikan terhadap keputusan menabung pada PT. Bank Danamon Indonesia Tbk Cabang Katamso Medan.

Kata kunci : Personal Selling; Kualitas Pelayanan; Keputusan Menabung.

\section{PENDAHULUAN}

Bank sebagai lembaga keuangan menyediakan berbagai jasa kebutuhan pelayanan bagi nasabah. Dalam menjalankan kegiatan, bank membutuhkan nasabah untuk semakin berkembang dan memperluas pelayanan. Oleh karena itu, maka bank harus memberikan pelayanan dan mampu memenuhi semua kebutuhan yang dibutuhkan oleh nasabah. Keputusan menabung adalah keputusan yang dimiliki oleh nasabah dalam memberikan sejumlah dana kepada bank untuk dipercayakan sebagai lembaga keuangan yang berfungsi untuk mendukung pemerintah. Keputusan menabung perlu dipertahankan oleh perusahaan agar dapat mengumpulkan target pengumpulan dana yang telah diberikan kepada perusahaan. Keputusan menabung yang tinggi memperlihatkan bahwa nasabah memiliki tingkat kepercayaan yang tinggi kepada bank.

\section{METODOLOGI PENELITIAN}

\section{Jenis Penelitian}

Jenis penelitian yang dilakukan adalah penelitian deskriptif kuantitatif yaitu dengan mengetahui pengaruh promosi dan kualitas pelayanan merek terhadap keputusan menabung. Penelitian kuantitatif dalam melihat hubungan variabel terhadap objek yang diteliti lebih bersifat sebab dan akibat (kausal) sehingga dalam penelitiannya ada variabel independen dan dependen.

\section{Populasi dan Sample}

Populasi adalah wilayah generalisasi yang terdiri dari objek/subjek yang mempunyai kualitas dan karakteristik tertentu yang ditetapkan oleh peneliti untuk dipelajari dan kemudian ditarik kesimpulannya. Sample pada penelitian 
ini diambil 245 responden, dengan pertimbangan bahwa jumkah tersebut diharapkan sudah dapat mewakili sebagai sample penelitian.

\section{Jenis dan Sumber Data}

Adapun jenis dan sumber data yang digunakan dalam penelitian adalah:

1) Data Primer

Menurut Sugiyono (2012: 225) sumber primer adalah data- data yang diperoleh peneliti dari daftar pertanyaan yang disebarkan kepada setiap responden dan melakukan wawancara kepada nasabah perusahaan serta data- data yang diperoleh dari perusahaan dan contohnya adalah kuesioner.

2) Data Sekunder

Menurut Sugiyono (2012: 225) sumber sekunder adalah data yang mendukung data primer yang peneliti peroleh dari studi dokumentasi dan studi perpustakaan contohnya adalah data pengumpulan dana, data penjualan personal, dan data komplain pelayanan.

\section{Uji Instrumen Penelitian}

1) Uji Validitas

Untuk menguji ketetapan kuesioner, akan dilakukan pretest terhadap 30 orang konsumen yang dipilih dalam penelitian ini. Uji validitas dilakukan dengan bantuan program software SPSS (Statistical Package for Social Science).

2) Uji Reliabilitas

Pengujian dilakukan dengan cara mencobakan kuesioner sekali saja, kemudian data yang diperoleh dianalisis dengan teknik tertentu, dalam hal ini teknik yang digunJMBakan adalah teknik Cronbach Alpha (a). Suatu variable dikatakan reliable jika memberikan nilai Cronbach Alpha $<0.60$ maka variable tersebut tidak reliable.

\section{Metode Analisis Data}

1) Uji Normalitas

Uji normalitas bertujuan untuk menguji apakah dalam model regresi, variabel pengganggu atau residual memiliki distribusi normal (Ghozali, 2013: 160-164). 
2) Uji Multikolinearitas

Uji multikolinearitas bertujuan untuk menguji apakah pada model regresi ditemukan adanya korelasi antar variabel bebas (independen). Model regresi yang baik seharusnya tidak terjadi korelasi antar variabel independen (Ghozali, 2013: 105-106). Untuk mendeteksi ada tidaknya multikolinearitas di dalam model regresi dapat dilihat dari nilai tolerance dan lawannya dan Variance Inflation Factor (VIF). Kedua ukuran ini menunjukan setiap variabel independen manakah yang dijelaskan oleh variabel independen lainnya.

3) Uji Heteroskedastisitas

Uji Heteroskedastisitas bertujuan untuk menguji apakah di dalam model regresi terjadi ketidaksamaan variabel dari residual suatu pengamatan ke pengamatan yang lain (Ghozali, 2013;139). Suatu model regresi yang baik adalah tidak terjadi heteroskedastisitas. Ada beberapa cara untuk mendeteksi ada atau tidaknya heteroskedastisitas dalam varian error terms untuk model regresi. Dalam penelitian ini akan di gunakan metode chart (Diagram Scatterplot).

4) Analisis Regresi Berganda

Model hubungan keputusan pembeli dengan variabel-variabel tersebut dapat disusun dalam fungsi atau persamaan sebagai berikut :

$\begin{array}{ll}\mathbf{Y = a +} & \quad-+\mathbf{e} \\ \text { Dengan } & : \\ \mathrm{Y} & =\text { Keputusan Menabung } \\ \mathrm{a} & =\text { Konstanta } \\ . . \quad & =\text { Koefisien Regresi } \\ . \quad & =\text { Personal Selling } \\ . \quad & =\text { Kualitas Pelayanan } \\ \mathrm{e} & =\text { Standar error }\end{array}$

5) Pengujian Hipotesis

a. Uji Signifikansi Simultan ( Uji F)

Uji $\mathrm{F}$ digunakan untuk menunjukkan apakah semua variabel independen yang dimasukkan dalam model mempunyai pengaruh secara bersama-sama terhadap variabel dependen (Ghozali, 2013: 98).

b. Uji Signifikansi Secara Parsial ( Uji t)

Pengujian t-test digunakan untuk menunjukan seberapa jauh pengaruh satu variabel independen terhadap variabel dependen (Ghozali, 2013: 98-99). Uji t digunakan untuk menguji sugnifikan koefisien regresi secara parsial atau pengaruh masing-masing variabel independen secara individual terhadap variabel dependen. 
6) Analisis Koefisien Determinasi $\left(\mathrm{R}_{2}\right)$

Koefisien determinasi $\left(\mathrm{R}_{2}\right)$ ditujukan untuk mengukur seberapa jauh kemampuan model dalam menerangkan variasi variabel dependen. Jika koefisien determinasi $\left(\mathrm{R}_{2}\right)$ semakin besar atau mendekati 1 , maka dapat dikatakan bahwa kemampuan variabel bebas (X) adalah besar terhadap variabel terikat $(\mathrm{Y})$. Hal ini berarti model yang digunakan semakin kuat untuk menerangkan pengaruh variabel bebas yang diteliti dengan variabel terikat sebaliknya, jika koefisien determinasi $\left(R_{2}\right)$ semakin kecil atau mendekati 0 maka dapat dikatakan bahwa kemampuan variabel bebas (X) terhadap variabel terikat (Y) semakin kecil ( Ghozali, 2013: 97).

\section{HASIL PENELITIAN DAN PEMBAHASAN}

\subsection{Uji Asumsi Klasik}

3.1.1

Uji Normalitas

Tabel 1.One-Sample Kolmogorov-Smirnov Test

\begin{tabular}{lll} 
& & $\begin{array}{l}\text { UNSTANDARDIZED } \\
\text { RESIDUAL }\end{array}$ \\
\hline $\mathrm{N}$ & & 245 \\
Normal Parametersa, ,b & Mean & .0000000 \\
& Std. Deviation & 6.27585436 \\
Most Extreme Differences & Absolute & .041 \\
& Positive & .041 \\
Kolmogoriv-Smirnov Z & Negative & -.031 \\
Asymp. Sig (2-tailed) & & .636 \\
& .813 \\
a. Test distribution is Normal. & \\
b. Calculated from data. &
\end{tabular}

Dari data output dapat dilihat bahwa nilai signifikansi $>0,05$ sehingga dapat disimpulkan bahwa data telah terdistribusi normal.

\subsubsection{Uji Multikolinearitas}

Tabel 2. Uji Multikolinearitas

Coefficientsa

\begin{tabular}{llcc}
\multicolumn{3}{c}{ Coefficientsa } \\
& & \multicolumn{2}{c}{$\begin{array}{c}\text { COLLINEARITY } \\
\text { STATISTICS }\end{array}$} \\
\hline Model & & Tolerance & VIF \\
1 & $\begin{array}{l}\text { (Constant) } \\
\text { PERSONAL_SELLING }\end{array}$ & .884 & 1.132 \\
& KUALITAS_PELAYANAN & .884 & 1.132
\end{tabular}

a. Dependent Variable: KEPUTUSAN_MENABUNG 
Hasil variabel personal selling dan kualitas pelayanan nilai VIF sebesar 1.132 lebih kecil dari 10 dan nilai tolerance sebesar 0.884 mendekati 1 . Hal ini menunjukkan tidak terjadi gejala multikolinearitas dan variabel memenuhi uji asumsi klasik.

\subsubsection{Heteroskedastisitas}

Gambar 1. Scatterplot

Scatterplot

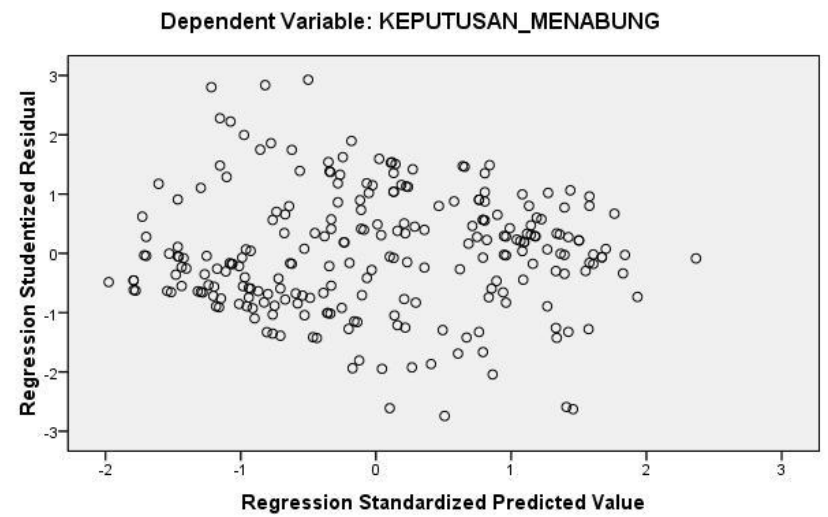

Dari hasil scatterplot terlihat titik yang menyebar yang tidak membentuk polapola tertentu dan tersebar baik di atas angka 0 dan berdasarkan gambar tersebut maka tidak terjadi heteroskedastisitas sehingga model regresi layak dipakai untuk memprediksi keputusan pembelian berdasarkan variabel independen.

\subsection{Analisis Regresi Berganda}

Tabel 3. Analisis Regresi Berganda COEFFICIENTSA

\begin{tabular}{|c|c|c|c|c|c|c|}
\hline \multirow[b]{3}{*}{ Model } & & \multicolumn{5}{|c|}{ Standardize } \\
\hline & & \multicolumn{2}{|c|}{$\begin{array}{l}\text { Unstandardized } \\
\text { Coefficients }\end{array}$} & $\begin{array}{c}\mathrm{d} \\
\text { Coefficients }\end{array}$ & \multirow[b]{2}{*}{$\mathrm{t}$} & \multirow[b]{2}{*}{ Sig. } \\
\hline & & B & Std. Error & Beta & & \\
\hline \multirow[t]{3}{*}{1} & (Constant) & 5.300 & 1.759 & & 3.014 & .003 \\
\hline & PERSONAL_SELLIN & .350 & .076 & .257 & 4.613 & .000 \\
\hline & $\begin{array}{l}\text { G } \\
\text { KUALITAS PELAYA }\end{array}$ & .415 & .052 & .442 & 7.953 & .000 \\
\hline
\end{tabular}

a. Dependent Variable: KEPUTUSAN_MENABUNG 
Berdasarkan tabel 3 , hasil analisis regresi diperoleh koefisien untuk Personal selling $\left(\mathrm{X}_{1}\right)$ sebesar 0,257 dan kualitas pelayanan $\left(\mathrm{X}_{2}\right)$ sebesar 0,442 . Sehingga diperoleh persamaan regresi berganda sebagai berikut :

Keputusan menabung $=5.300+0.350$ Personal Selling +0.415 Kualitas Pelayanan

Dari persamaan regresi tersebut, maka dapat disimpulkan sebagai berikut :

1) Nilai konstanta a sebesar 5.300 artinya bahwa jika tidak terdapat variabel personal selling $\left(\mathrm{X}_{1}\right)$ dan kualitas pelayanan $\left(\mathrm{X}_{2}\right)=0$ maka keputusan menabung akan bernilai sebesar 5.300 satuan.

2) Variabel Personal Selling $\left(\mathrm{X}_{1}\right)$ sebesar 0,350 yang artinya bahwa setiap kenaikan variabel personal selling sebesar 1 satuan, maka nilai pada keputusan menabung akan naik 0,350 satuan dengan asumsi bahwa variabel yang lain tetap.

3) Variabel Kualitas Pelayanan $\left(\mathrm{X}_{2}\right)$ sebesar 0,415 yang artinya bahwa setiap kenaikan variabel kualitas pelayanan sebesar 1 satuan, maka nilai pada keputusan menabung akan naik 0,415 satuan dengan asumsi bahwa variabel yang lain tetap.

\subsection{UJi Hipotesis}

\subsubsection{Uji Signifikansi Simultan ( Uji F)}

Hasil dari Uji F dapat dilihat pada Tabel dibawah ini :

Tabel 4. Uji F

\begin{tabular}{lrrrrr}
\multicolumn{7}{c}{ ANOVAb } & & & \\
\multicolumn{1}{c}{ Model } & Sum Of Squares & df & Mean Square & F & Sig. \\
\hline $\begin{array}{l}\text { Regression } \\
\text { Residual }\end{array}$ & 4922.180 & 2 & 2461.090 & 61.974 & $.000 a$ \\
Total & 9610.269 & 242 & 39.712 & & \\
\hline a. & Predictors: (Constant), KUALITAS_PELAYANAN, PERSONAL_SELLING & \\
b. & Dependent Variable: KEPUTUSAN_MENABUNG
\end{tabular}

Berdasarkan Tabel 4 , diperoleh hasil $\mathrm{F}$ Hitung 61.974 sedangkan $\mathrm{F}$ Tabel pada $\mathrm{a}=$ 0,05 diperoleh dari sumber probabilitas $F_{\text {tabel }}$ yang tersedia yaitu 3.033125 dari hasil ini diketahui $\mathrm{F}$ hitung $>\mathrm{F}$ tabel, dan signifikansi 0,000 atau lebih kecil dari a = 0,05 jadi posisi titik uji signifikansi berada pada wilayah Personal selling dan kualitas pelayanan secara bersama-sama berpengaruh positif dan signifikan terhadap variabel keputusan menabung. 


\subsubsection{Uji Signifikansi secara Parsial ( Uji t)}

Hasil Uji t pada penelitian ini dapat dilihat pada Tabel berikut :

Tabel 5. Uji t

Coefficientsa

\begin{tabular}{lrrrrr}
\hline Model & \multicolumn{2}{c}{$\begin{array}{c}\text { Unstandardized } \\
\text { Coefficients }\end{array}$} & $\begin{array}{c}\text { Standardized } \\
\text { Coefficients }\end{array}$ & T & Sig. \\
\cline { 2 - 4 } & \multicolumn{1}{c}{$\begin{array}{c}\text { Std. } \\
\text { Error }\end{array}$} & & & \\
\hline (Constant) & 5.300 & 1.759 & & 3.014 & .003 \\
Personal_Selling & .350 & .076 & .257 & 4.613 & .000 \\
Kualiats_Pelayanan & .415 & .052 & .442 & 7.953 & .000 \\
\hline
\end{tabular}

a. Dependent Variable: KEPUTUSAN_MENABUNG

Berdasarkan Tabel 5 , hasil uji parsial diperoleh sebagai berikut:

a) Nilai $t$ hitung untuk variabel personal selling (4.613) lebih dominan dibandingkan dengan nilai t tabel (2.255435) atau nilai sig t untuk variabel personal selling $(0,000)$ lebih kecil dari a $(0,05)$.

Berdasarkan hasil yang diperoleh maka menolak Ho dan menerima $\mathrm{H}_{a}$ untuk variabel personal selling. Dengan demikian, secara parsial personal selling berpengaruh positif dan signifikan terhadap keputusan menabung. Hal ini memberi arti bahwa personal selling memberikan dampak pada keputusan menaubng.

b) Nilai t hitung untuk variabel kualitas pelayanan (7.953) lebih dominan dibandingkan dengan nilai t tabel (2.255435) atau nilai sig t untuk variabel kualitas pelayanan $(0,000)$ lebih kecil dari a $(0,05)$. Berdasarkan hasil yang diperoleh maka menolak $\mathrm{H}_{0}$ dan menerima $\mathrm{H}_{\mathrm{a}}$ untuk variabel kualitas pelayanan. Dengan demikian, secara parsial kualitas pelayanan berpengaruh positif dan signifikan terhadap keputusan menabung. Hal ini memberi arti bahwa kualitas pelayanan dari perusahaan memberikan dampak pada keputusan menabung. 


\subsection{Analisis Koefisien Determinasi (R2)}

Tabel 6. Analisis Koefisien Determinasi

Model Summaryb

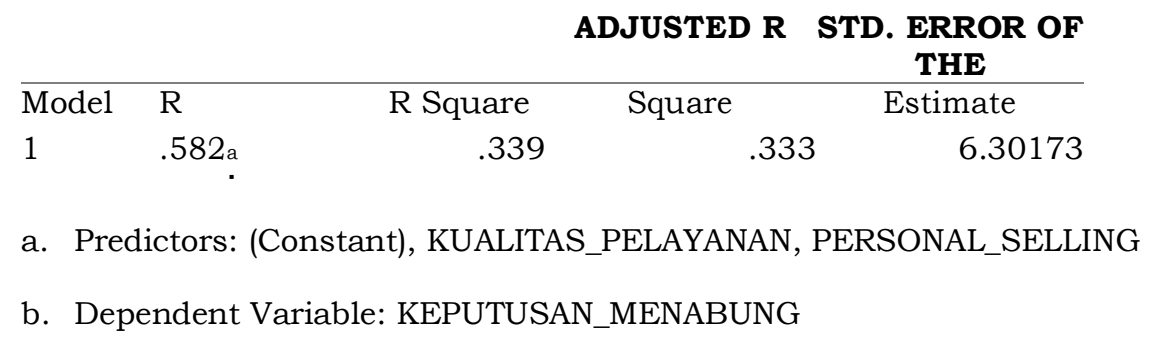

Berdasarkan hasil tabel diatas nilai Adjusted $R$ Square adalah 0,333 artinya bahwa kemampuan variasi variabel personal selling $\left(\mathrm{X}_{1}\right)$ dan kualitas pelayanan $\left(\mathrm{X}_{2}\right)$ dapat menjelaskan variasi dari keputusan menabung adalah sebesar $33,3 \%$.

\section{Pembahasan}

Berdasarkan hasil penelitian yang menguji antara variabel independen (personal selling dan kualitas pelayanan) terhadap variabel dependen (Keputusan menabung), maka ada beberapa hal yang dapat dijelaskan dalam penelitian ini yaitu sebagai berikut :

1) Personal Selling $\left(\mathrm{X}_{1}\right)$ berpengaruh terhadap keputusan menabung

Hasil penelitian yang dilakukan peneliti membuktikan bahwa adanya pengaruh personal selling terhadap keputusan menabung. Hal ini dapat dilihat dari hasil uji parsial (Uji-t) dimana nilai thitung $>$ tabel $(4.613>2.255435)$. Sehingga hasil penelitian menolak $\mathrm{H}_{0}$ dan menerima $\mathrm{H}_{\mathrm{a}}$. Personal selling berperan penting terhadap keputusan menabung, karena perusahaan menggunakan variabel personal selling untuk meningkatkan keputusan menabung. Oleh Karena itu perusahaan harus lebih inovatif lagi dalam meningkatkan personal sellingnya agar dapat menarik nasabah sehingga keputusan menabung dalam membeli produk tabungan, deposito, giro semakin meningkat.

2) Kualitas pelayanan $\left(\mathrm{X}_{2}\right)$ berpengaruh terhadap keputusan menabung. Hasil penelitian yang dilakukan penliti membuktikan bahwa adanya pengaruh kualitas pelayanan terhadap keputusan menabung. Hal ini dapat dilihat dari hasil uji parsial (Uji-t) dimana nilai thitung $>$ ttabel $(7.953>2.255435)$. Sehingga hasil penelitian menolak $\mathrm{H}_{0}$ dan menerima $\mathrm{H}_{\mathrm{a}}$. Dalam impretasinya semakin besar kualitas pelayanan, maka akan sangat mempengaruhi keputusan menabung. Tetapi jika kualitas pelayanan mengalami penurunan, maka produk Bank Danamon akan mengalami penurunan terhadap keputusan menabung. Oleh karena perusahaan memiliki kualitas pelayanan yang baik maka produknya akan selalu dicari oleh nasabah. 


\section{PENUTUP}

\section{Kesimpulan}

1) Hasil pegujian secara parsial variabel personal selling berpengaruh signifikan terhadap keputusan menabung pada PT. Bank Danamon Indonesia Tbk Cabang Katamso Medan.

2) Hasil pengujian secara parsial variabel kualitas pelayanan berpengaruh signifikan terhadap keputusan menabung pada PT. Bank Danamon Indonesia Tbk Cabang Katamso Medan.

3) Hasil pengujian secara simultan variabel personal selling (X1) dan kualitas layanan (X2) secara serempak berpengaruh positif dan signifikan terhadap keputusan menabung pada PT. Bank Danamon Indonesia Tbk Cabang Katamso Medan.

4) Hasil pengujian koefisien determinasi menunjukkan bahwa nilai Adjusted $R$ Squared sebesar 0,333 yang artinya sebesar 33,3\% dapat dijelaskan oleh pengaruh personal selling dan kualitas pelayanan terhadap keputusan menabung pada PT. Bank Danamon Indonesia Tbk Cabang Katamso Medan dan sisanya sebesar 66,7\% di variasi oleh variabel lain yang tidak di teliti seperti bukti fisik dan lokasi kantor.

\section{Saran}

Saran-saran yang dapat diajukan :

1) Personal selling PT. Bank Danamon Indonesia Tbk Cabang Katamso Medan harus bisa memberikan nasabah kepuasan dalam kualitas pelayanan untuk keputusan menabung sehingga nasabah tidak kecewa dan juga dapat berpindah ke bank lain. Selain itu PT. Bank Danamon Indonesia Tbk Cabang Katamso Medan harus dapat meningkatkan kinerja personal selling dan kualitas pelayanan nya.

2) Bagi peneliti selanjutnya sebaiknya memasukkan variabel lain selain personal selling dan kualitas pelayanan sebagai predictor variabel bagi keputusan menabung, sehingga dapat diperoleh informasi yang lebih banyak tentang faktor-faktor yang dapat mempengaruhi kinerja karyawan.

3) Bagi perguruan tinggi dapat menyimpan penelitian ini dan dapat menjadi acuan bagi mahasiswa yang ingin melakukan penelitian yang berkaitan dengan variabel yang diteliti dalam penelitian ini. 


\section{DAFTAR PUSTAKA}

Abdullah, Thamrin dan Francis Tantri. 2014.Manajemen Pemasaran. Ed. 1, Jakarta: PT RajaGrafindo Persada.

Abdul, Mus Eflis (2018) Jurnal Gorontalo Management Research Vol.1 No.1 2018 Persepsi Bauran Pemasaran Terhadap Kepuasan Pelanggan Di Percetakan Tiara Limboto Kabupaten Gorontalo

Adisaputro, Gunawan. 2015. Manajemen Pemasaran. Cetakan Kedua. Yogyakarta: UPP STIM YKPN

Doresa, Esa Sela. 2017. Pengaruh Personal Selling dan Sales Promotion terhadap Keputusan Pembelian di Butik Mezora Malang.

Ghozali, Imam. 2013. Aplikasi Analisis Multivariate dengan Program IBM SPSS 21. Cetakan Ketujuh. Semarang: Universitas Diponegoro.

Girad, Scott L, 2014. dkk. Sales dan Marketing: Menjadi Marketing Andal dan Profesional. Solo: PT. Tiga Serangkai.

Haryono, Budi. 2016. How to win Customer Through Customer Service With Heart. Yogyakarta: CV. Andi Offset.

Hasan, Ali. 2013. Marketing dan Kasus-kasus Pilihan. Penerbit CAPS, Yogyakarta. Herlambang, Susatyo. 2014. Basic Marketing (Dasar-Dasar Pemasaran): Cara Mudah Memahami Ilmu Pemasaran. Yogyakarta: Gosyen Publishing.

Hermawan, Agus. 2012. Komunikasi Pemasaran. Malang: Erlangga.

Lupiyoadi, Rambat. 2013. Manajemen Pemasaran Jasa. Ed.3, Penerbit Salemba Empat, Jakarta.

Manap. Abdul. 2016. Revolusi Manajemen Pemasaran. Jakarta: Mitra Wacana Media.

Marwanto. Aris. 2015. Marketing Sukses. Penerbit Kobis. Yogyakarta.

Mayasari. Hesti. 2017. Pengaruh Motivasi dan Kualitas Pelayanan Terhadap Keputusan Menabung di Bank Sinarmas Syariah Padang.

Nitisusastro, Mulyadi. 2013. Perilaku Konsumen dalam perspektif kewirausahaan, Cetakan Kedua. Bandung: Alfabeta.

Rangkuti, Freddy. 2009. Strategi Promosi yang Kreatif dan Analisis. Kasus. Integrated Marketing Communication. Jakarta 
Rangkuti, Freddy. 2013. Teknik Membedah Kasus Bisnis Analisis SWOT Cara Perhitungan Bobot, Rating dan OCAI. Jakarta: Gramedia Pustaka.

Sangadji, Etta Mamang \& Sopiah. 2013. Perilaku Konsumen Pendekatan Praktis Disertai Himpunan Jurnal Penelitian. Yogyakarta: CV Andi Offset (Penerbit Andi)

Sarwita, Ade. 2017. Pengaruh Kualitas Pelayanan dan Promosi Terhadap Keputusan Nasabah untuk Menabung pada Perumda BPR Majalengka.

Suchaeri, Heri. 2012. Total Customer Percepatan Laba Sepanjang Masa. Solo: PT Tiga Serangkai Pustaka Mandiri.

Sudaryono. 2015. Pengantar Bisnis (Teori\&ContohKasus). EdisiPertama. Yogyakarta: CV ANDI.

Setiadi, Nugroho J.2015. Perilaku Konsumen : Konsep Dan Implikasi Untuk Strategi Dan Penelitian Pemasaran. Jakarta: Kencana Prenada Media Group.

Sugiyono. 2012. Metode Penelitian Bisnis (Pendekatan Kuantitatif, Kualitatif, dan R\&D). Cetakan 16. Bandung: CV. Alfabeta.

Sunyoto, Danang. 2014. Teori, Kuesioner \& Analisis Data Untuk Pemasaran dan Perilaku Konsumen. Yogyakarta: Graha Ilmu.

Sunyoto, Danang. 2013. Kewirausahaan untuk Kesehatan. Yogyakarta: Graha Ilmu.

Suparyanto dan Rosad. 2015. Manajemen Pemasaran. Bogor: In Media. Supranto, J. \& Nandan Limakrisna. 2011. Perilaku Konsumen \& Strategi Pemasaran : Untuk Memenangkan Persaingan Bisnis. Ed. 2, Jakarta: Mitra Wacana Media.

Supranto, 2011. Pengukuran Tingkat Kepuasan Pelanggan untuk Menaikkan Pangsa Pasar. Jakarta. Penerbit Rineka Cipta.

Tjiptono, Fandy. 2015 Strategi Pemasaran, Edisi ketiga, Yogyakarta.Penerbit Andi.

Tjiptono. $\quad$ Fandy. 2012. Service Management Mewujudkan Layanan Prima. Yogyakarta. CV Andi Offset.

Zulganef. 2008. Metode Penelitian Sosial dan Bisnis. Yogyakarta: Graha Ilmu. 